\title{
Activating EML4/ALK Gene Mutation
}

National Cancer Institute

\section{Source}

National Cancer Institute. Activating EMLAIALK Gene Mutation. NCI Thesaurus. Code C150436.

A change in the nucleotide sequence of the ALK portion of the EML4/ALK fusion gene that that results in constitutive activation of the EML4/ALK fusion protein and its downstream signaling pathways. These mutations are associated with increased oncogenic potential. 